\title{
Modernización del Catastro de Mérida (México). Un caso de éxito
}

\section{Dirección de Catastro del Municipio de Mérida*}

Recibido el 29 de mayo de 2014; aceptado el 3 de julio de 2014

\begin{abstract}
This article refers the situation that use to have the Municipality's Land Registry of Mérida, Yucatán, Mexico before implement the Modernization's program in 2009, this process began with a land register diagnosis and an executive project, also contains the benefits of improvement as a result of the modernization in the service development and in tax income.

Key words: land registry, diagnosis, program, modernization, service development.
\end{abstract}

\section{Resumo}

O artigo se refere a situação do cadastro do Município de Mérida, Yucatán, México, antes de implementar-se o Programa de Modernização no ano de 2009; descreve o processo de adesão ao programa a partir do Diagnóstico Cadastral e Projeto Executivo, assim como o melhoramento e os benefícios que se refletiram na operatividade dos serviços e na arrecadação como resultado da modernização.

Palavras chave: cadastro, diagnóstico, programa, modernização, desenvolvimento de serviços.

\section{Resumen}

El artículo refiere la situación del catastro del Municipio de Mérida, Yucatán, en México antes de implementarse el Programa de Modernización en el año 2009; describe el proceso de adhesión al programa, a partir del Diagnóstico Catastral y el Proyecto Ejecutivo, así como el mejoramiento y los beneficios que se reflejaron en la operatividad de los servicios y la recaudación como resultado de la modernización.

* Calle 65 No. 503 por 60 y 62 Centro, 97000 Mérida, Yucatán, correo electrónico: catastro@merida.gob.mx 
Palabras clave: Catastro, diagnóstico, programa, modernización, desarrollo de servicios.

\section{Situación del catastro antes de implementar el Programa de Modernización}

En el periodo 2000-2009 la Dirección de Catastro del Municipio de Mérida, estableció un organigrama con las funciones básicas para cumplir con el objetivo del registro catastral, que permitió dar servicio a los usuarios del ámbito privado y público (véase Figura 1).

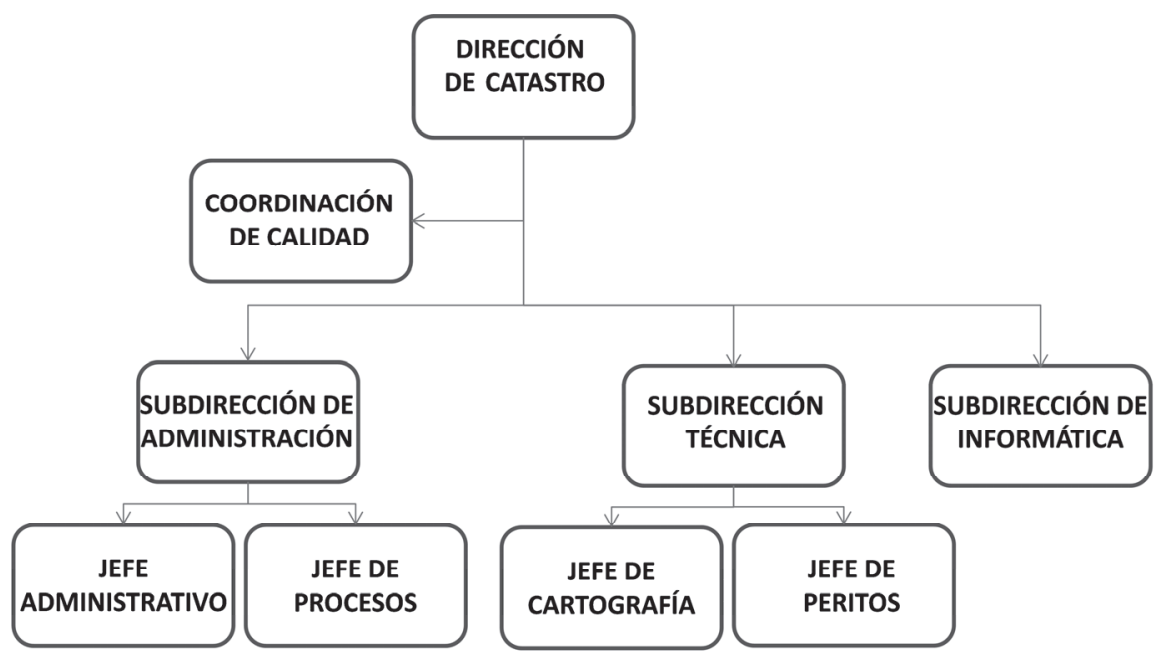

Figura 1. Organigrama de la Dirección de Catastro del Municipio de Mérida hasta el año 2009.

\section{Esquema y procedimiento de atención al público}

La Subdirección de Administración se encargaba de ejecutarlas tareas de control de servicios, por medio de la Jefatura de Procesos y de la Coordinación de Archivos.

La Subdirección Técnica ejecutaba las tareas técnicas de Cartografía, Peritos y Nomenclatura.

La Subdirección de Informática proporcionaba el soporte a la base de datos, la integración de SIG y el desarrollo de software.

En la Figura 2 se muestra el tránsito de la solicitud de un servicio, desde que el usuario lo ingresa a las ventanillas y hasta el momento en que el trámite es concluido y entregado al usuario. 
Procesos relacionados con la gestión de los servicios y seguimiento de indicadores de control Diagrama de Interacción de los Procesos:

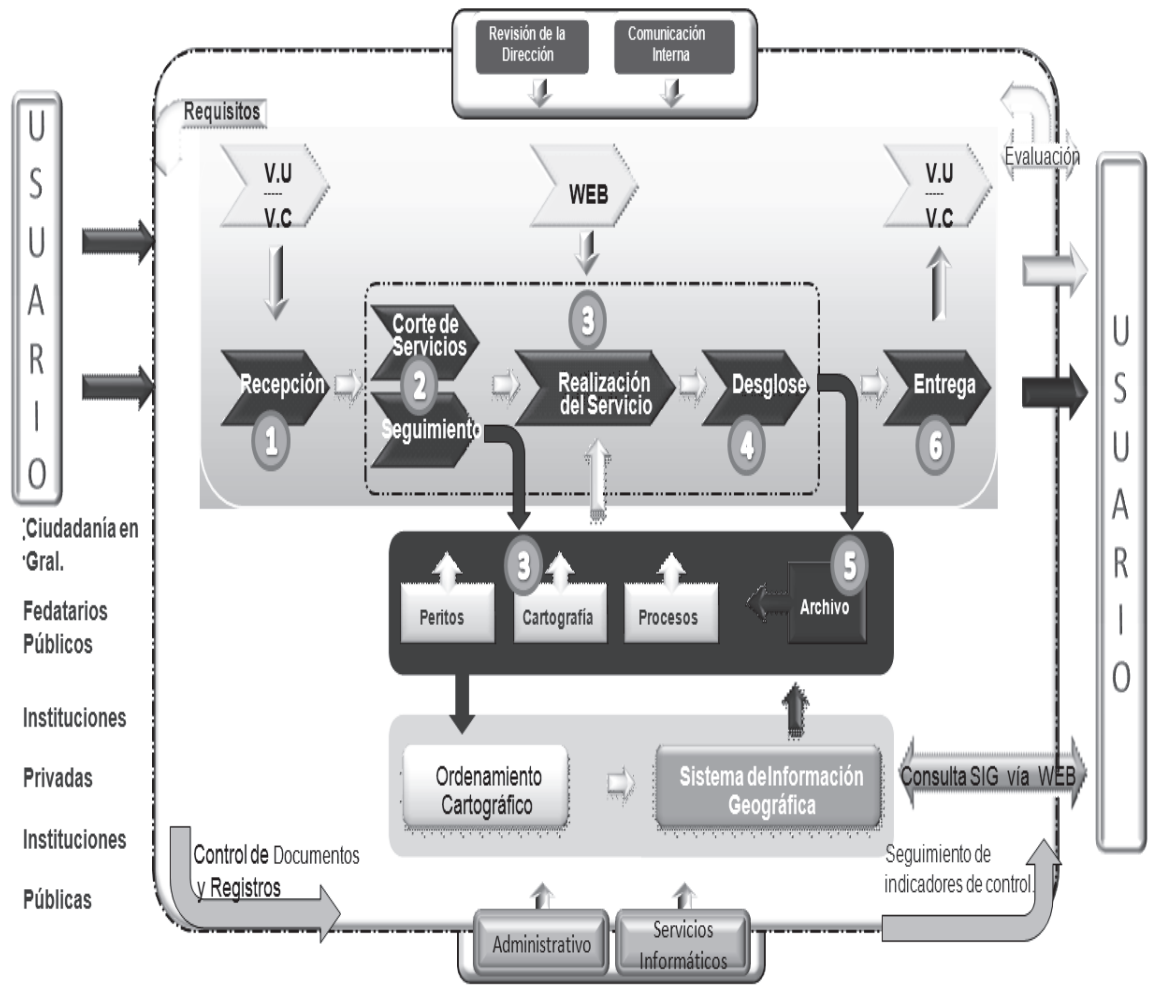

Siglas empleadas en el diagrama:

V.U. Ventanilla Única

V.C. Ventanilla en Catastro

WEB. Vía portal de Internet

Figura 2. Esquema de procedimiento empleado en la prestación de servicios catastrales.

\section{Tiempo promedio de atención al público en los principales servicios catastrales}

El tiempo promedio de atención al público en los servicios catastrales para el periodo 2007-2008 se muestra en la Tabla 1.

\section{Medios a través de los cuales el contribuyente solicita y/o tramita servicios catastrales}

Ventanillas únicas. Se gestionan de manera inmediata los servicios o trámites que no requieren la atención de áreas técnicas. 


\section{Tabla 1}

Tiempo de realización de principales servicios catastrales

\begin{tabular}{|c|c|c|c|c|c|}
\hline $\begin{array}{l}\text { Tipo de } \\
\text { trámite }\end{array}$ & $\begin{array}{l}\text { Trámites por } \\
\text { año }\end{array}$ & $\begin{array}{c}\text { Tiempo } \\
\text { promedio } \\
\text { por trámite }\end{array}$ & $\begin{array}{c}\text { Tiempo } \\
\text { promedio } \\
\text { de espera } \\
\text { en la fila }\end{array}$ & $\begin{array}{c}\text { Tiempo } \\
\text { promedio } \\
\text { de } \\
\text { entrega }\end{array}$ & $\begin{array}{c}\text { Veces que } \\
\text { regresa el } \\
\text { usuario } \\
\text { para con- } \\
\text { cluir su } \\
\text { trámite }\end{array}$ \\
\hline $\begin{array}{l}\text { Elaboración de } \\
\text { planos con } \\
\text { visita a } \\
\text { campo }\end{array}$ & 1,003 & 7 horas & $\begin{array}{c}60 \\
\text { minutos }\end{array}$ & 9 días & 1 \\
\hline $\begin{array}{l}\text { División } \\
\text { (Proyecto) }\end{array}$ & 1,436 & 8 horas & $\begin{array}{c}60 \\
\text { minutos }\end{array}$ & 10 días & 0 \\
\hline $\begin{array}{l}\text { Diligencia de } \\
\text { verificación }\end{array}$ & $942 *$ & 7 horas & $\begin{array}{c}60 \\
\text { minutos }\end{array}$ & 9 días & 2 \\
\hline $\begin{array}{l}\text { Traslado de } \\
\text { dominio } \\
(2007)^{* *}\end{array}$ & 1,354 & $4: 29$ horas & $\begin{array}{l}60 \\
\text { minutos }\end{array}$ & 7 horas & 0 \\
\hline
\end{tabular}

Fuente: Catastro del Municipio de Mérida. Reporte de Indicadores de los Principales Servicios Concluidos.

Tabla 2

Uso de la información catastral por otras direcciones del Municipio de Mérida

\begin{tabular}{ll}
\hline \multicolumn{1}{c}{ Dependencia } & \multicolumn{1}{c}{ Proyecto } \\
\hline Finanzas & $\begin{array}{l}\text { Integración al Sistema de Ingresos y mapeo del pago de } \\
\text { impuesto predial por colonia } \\
\text { Integración al Sistema de Población } \\
\text { Gobernación }\end{array}$ \\
$\begin{array}{l}\text { Servicios Públicos } \\
\text { Municipales }\end{array}$ & Nomenclatura \\
Finanzas & Integración al Sistema de Ingresos \\
Obras Públicas & Inversión por colonia en obra pública \\
Desarrollo Urbano & Manifiesto de obra \\
\hline
\end{tabular}


Ventanillas de Servicios Catastrales. Servicios especializados que brinda el Catastro y es posible solicitarlos en ventanilla única.

Vía web. Desde el año 2007, existe una página web que permite realizar trámites en línea o carrito electrónico.

\section{Uso y compartición de la información catastral por otras áreas del Municipio}

El Catastro Municipal constituye una fuente permanente de información para el ordenamiento urbano, como tal se logró realizar una metodología para compartir información con otras dependencias municipales; la información que se comparte es de tipo alfanumérico (como catálogos de unidades habitacionales, poblaciones, secciones catastrales, etcétera) e información geográfica (cartografía a nivel de predio, manzanas, calles, unidades habitacionales, tablajes, equipamiento urbano, etcétera, véase Tabla 2).

\section{Grado de implementación de un Sistema de Información Geográfica}

Se consideró el proyecto de un Centro Geomático aplicado al municipio, en el que se definieron tres etapas para su consolidación: 1) creación, 2) mantenimiento y 3) producción.

Inició en diciembre de 2005 y hasta la fecha de elaboración de este documento se concretaron las dos primeras etapas. El Catastro es el responsable de la administración, creación y mantenimiento de la base de datos geográfica y alfanumérica.

\section{Grado de actualidad y oportunidad en la actualización de la información catastral}

\section{Cartografía}

La cartografía está basada en la Cartografía Censal del año 2000 del Instituto Nacional de Estadística y Geografía (INEGI), referida al sistema ITRF92 y proyección UTM (Universal Transversa de Mercator) que es un sistema de coordenadas basado en la proyección cartográfica transversa de Mercator, que se construye como la proyección de Mercator normal, pero en vez de hacerla tangente al Ecuador se la hace tangente a un meridiano.

Consta de 50 secciones: de la 1 a la 30 para el área urbana y de la 31 a la 50 para el área rural o comisarías del municipio (véase Tabla 3 ).

La base cartográfica se actualiza y complementa con la realización de levantamientos geodésicos y topográficos para los servicios brindados al contribuyente.

La actualización cartográfica se realizaba mediante la edición e integración de dibujos en software tipo CAD, en esta actividad intervenían las coordinaciones de Topografía, Ordenamiento Cartográfico y Análisis de Información Cartográfica. En este contexto, la Dirección de Catastro visualizó la realización de un vuelo foto- 
gramétrico para integrar una base de cartografía actualizada, producto de la restitución del mismo.

Tabla 3

Secciones catastrales

\begin{tabular}{ccccccc}
\hline Secciones & Manzanas & $\begin{array}{c}\text { Etiquetas } \\
\text { de } \\
\text { manzana }\end{array}$ & Predios & Folios & Tablajes & Parcelas \\
\hline 50 & 15,796 & 15,620 & 268,942 & 70,254 & 11,388 & 9,354 \\
\hline
\end{tabular}

\section{Eficiencia de la recaudación predial}

\section{Recaudación fiscal}

En la Figura 3 se muestra el incremento de la recaudación predial antes de implementar el Programa de Modernización en el año 2009.

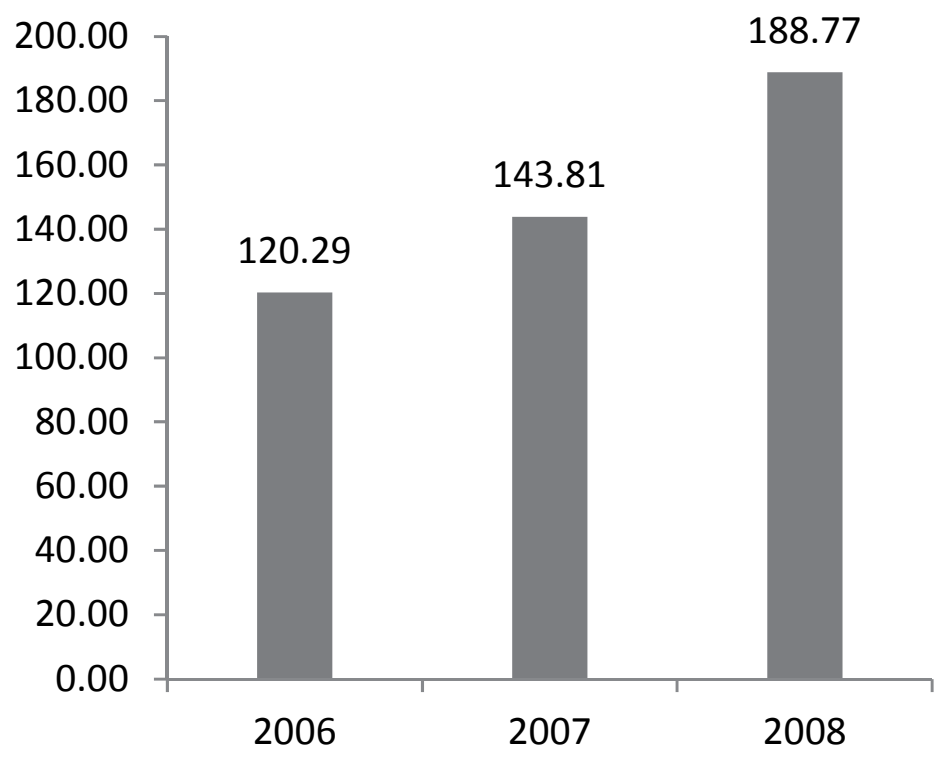

- Cantidades en millones de pesos

Figura 3. Recaudación del Impuesto Predial 2006-2008.

Fuente: Dirección de Finanzas y Tesorería Municipal. 


\section{Adhesión al Programa de Modernización}

\section{Áreas de oportunidad detectadas en el Diagnóstico Catastral}

El municipio de Mérida, Yucatán, realizó un convenio con el Banco Nacional de Obras y Servicios Públicos (BANOBRAS) y, con la participación del INEGI, se desarrolló un Diagnóstico Catastral en el año 2008, con la finalidad de determinar los requerimientos del área para acceder al Programa de Modernización Catastral.

\section{Acciones del Proyecto Ejecutivo}

Con el resultado que se obtuvo del Diagnóstico Catastral, se plantearon las acciones para consolidar el Proyecto de Modernización (véase Tabla 4).

\section{Tabla 4}

\begin{tabular}{ll}
\hline \multicolumn{1}{c}{ Acciones recomendadas del plan de acción } \\
\hline - Actualización de la base cartográfica mediante la ejecución de proyecto \\
fotogramétrico con vuelos a escala 1:5,000 y 1:20,000 \\
- Análisis y depuración de información \\
- Redefinición de procedimientos y funciones por área \\
- Ajuste al Sistema de Gestión Catastral (SIGESCAT) \\
- Ajustes al Sistema de Información Geográfica Municipal \\
- Implementar el Sistema de Mantenimiento Cartográfico \\
- Optimización del equipo de cómputo y software \\
\hline
\end{tabular}

\section{Costo total de implementación del Proyecto Ejecutivo}

La Tabla 5 muestra los conceptos y los costos erogados para su ejecución y también las actividades realizadas por personal de la institución catastral.

\section{Productos geográficos adquiridos mediante el Programa de Modernización}

Base cartográfica actualizada

Para la actualización de la base cartográfica se requirió un proyecto fotogramétrico considerando para esto un vuelo a escala 1:5,000 para zonas urbanas y a escala 1:20,000 para zonas poco habitadas o urbanizadas, pero con atributos importantes y de relevancia para el Sistema de Información Geográfica del Municipio de Mérida. 
Tabla 5

Costo de inversión para implementar el Proyecto Ejecutivo

\begin{tabular}{lccr}
\hline \multicolumn{1}{c}{ Concepto } & $\begin{array}{c}\text { Unidad de } \\
\text { medida }\end{array}$ & Cantidad & $\begin{array}{r}\text { Costo ejercido en } \\
\text { moneda nacional }\end{array}$ \\
\hline $\begin{array}{l}\text { Actualización de la base } \\
\text { cartográfica }\end{array}$ & $\mathrm{km}^{2}$ & $874.04 \mathrm{~km}^{2}$ & $6,354,702.20$ \\
$\begin{array}{l}\text { Análisis y depuración } \\
\text { Redefinición de } \\
\text { procedimientos }\end{array}$ & Predio & 119,692 & $826,297.91$ \\
$\begin{array}{l}\text { Ajuste al SIGESCAT } \\
\text { Ajustes al SIG municipal }\end{array}$ & Manual de & Interno & 0.00 \\
$\begin{array}{l}\text { Mantenimiento del } \\
\text { sistema cartográfico }\end{array}$ & Sistema & Interno & 0.00 \\
$\begin{array}{l}\text { Equipo de cómputo, } \\
\text { software y equipamiento }\end{array}$ & Lurso Taller & 1 & 0.00 \\
$\begin{array}{l}\text { Supervisión del proyecto } \\
\text { Presupuesto ejercido }\end{array}$ & Reporte & 1 & $2,844,999.69$ \\
\hline
\end{tabular}

\section{Principales acciones ejecutadas}

- Supervisión y ejecución del proyecto fotogramétrico. Inició con la capacitación sobre conceptos básicos de fotogrametría al personal del Catastro de Mérida, entendiendo fotogrametría como la técnica para determinar las propiedades geométricas de los objetos y las situaciones espaciales a partir de imágenes fotográficas.

- Vuelo fotogramétrico a escala 1:5,000 con resolución de $10 \mathrm{~cm}$. La cobertura contemplada se cubrió con un vuelo fotogramétrico integrado por 2,759 imágenes, de las que surgieron las ortofotos (representación mediante una fotografía de la superficie terrestre en la que los elementos presentan la misma escala libre de errores y deformaciones) a escala 1:1,000.

- Vuelo fotogramétrico a escala 1:20,000 con resolución de 30cm. Las áreas de interés fueron totalmente cubiertas por el vuelo fotogramétrico y se generaron 458 imágenes, de las cuales se derivaron las ortofotos a escala 1:5,000. En ambos vuelos se vigiló el cumplimiento de los estándares de calidad y las normas vigentes.

- Control de calidad del apoyo terrestre. Foto identificación, verificación y medición de cinco puntos de apoyo terrestre monumentados y distribuidos en todo el 
bloque fotogramétrico, para evaluar la exactitud de los productos a entregar por la empresa contratada.

El proceso de restitución fotogramétrica se realizó utilizando estaciones de restitución digital y software especializado para tales propósitos.

- Información base. La información base para el proceso de restitución la conforman los pares estereoscópicos obtenidos del vuelo fotogramétrico con resolución de 10 y $30 \mathrm{~cm}$, los cuales fueron verificados en la estación fotogramétrica AU4 perteneciente al Catastro de Mérida.

La información está georreferenciada y ligada a la Red Geodésica Nacional. Se emplea la Proyección Universal Transversa de Mercator (UTM), como sistema cartográfico de representación.

- Restitución de niveles de información. Una vez creado el proyecto en la estación fotogramétrica, con los datos de orientación externa obtenidos del proceso de aerotriangulación, se procedió a la restitución fotogramétrica digital en la que se compilaron las siguientes capas de información, de acuerdo con la Tabla 6, aceptada por el Departamento de Catastro.

Tabla 6

Capas de información de la restitución fotogramétrica realizada en el año 2009 en la ciudad de Mérida, Yucatán

\begin{tabular}{lccc}
\hline \multicolumn{1}{c}{ Grupo } & Línea & Polígono & Punto \\
\hline Altimetría & $\mathrm{x}$ & & \\
Hidrología & $\mathrm{x}$ & $\mathrm{x}$ \\
Infraestructura urbana & & $\mathrm{x}$ & \\
Planimetría & & $\mathrm{x}$ \\
Polígono de unidad habitacional & & \\
Vías de comunicación & $\mathrm{x}$ & \\
Zonas arqueológicas & $\mathrm{x}$ & \\
\hline
\end{tabular}

Fuente: $\quad$ Catastro del Municipio de Mérida. Capas de información de la restitución fotogramétrica.

\section{Beneficios del Programa de Modernización}

Entre los beneficios más significativos surgieron las nuevas opciones de contacto y/o trámite de servicios que tiene el contribuyente después de la implementación del Programa de Modernización. Se han creado 38 nuevos servicios en las ventanillas únicas y catastrales, se implementó un portal con los servicios de "carrito electrónico" en línea con servicios catastrales y con servicios de otras dependencias tales como licencias de uso de suelo de desarrollo urbano y pago del impuesto sobre adquisición de inmuebles de finanzas y tesorería. 


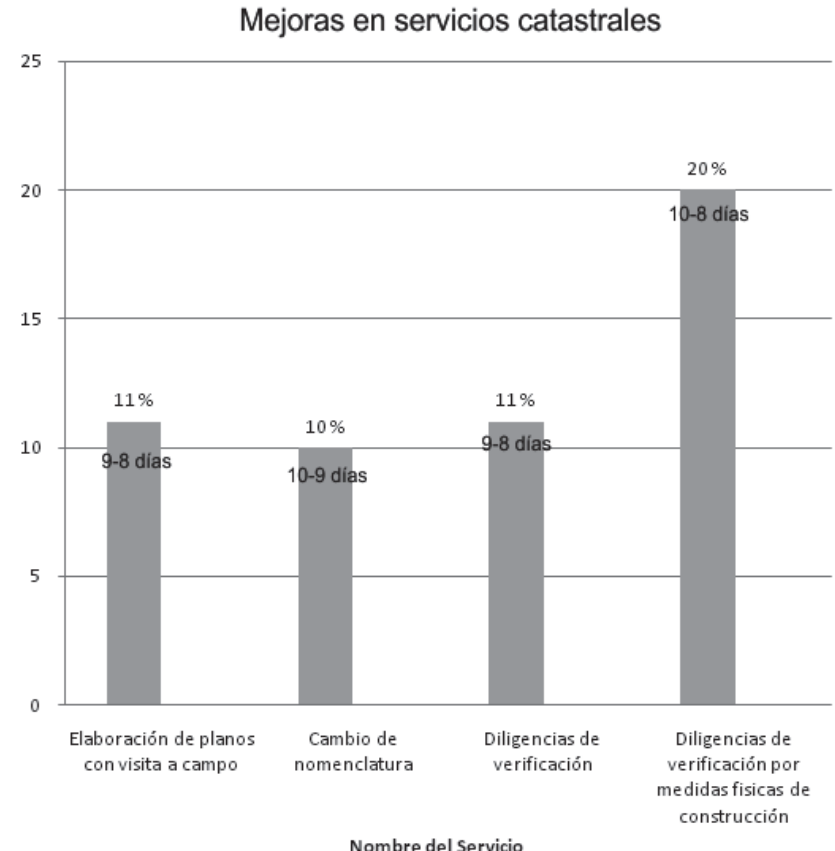

\section{Servicios atendidos en el mes de noviembre}

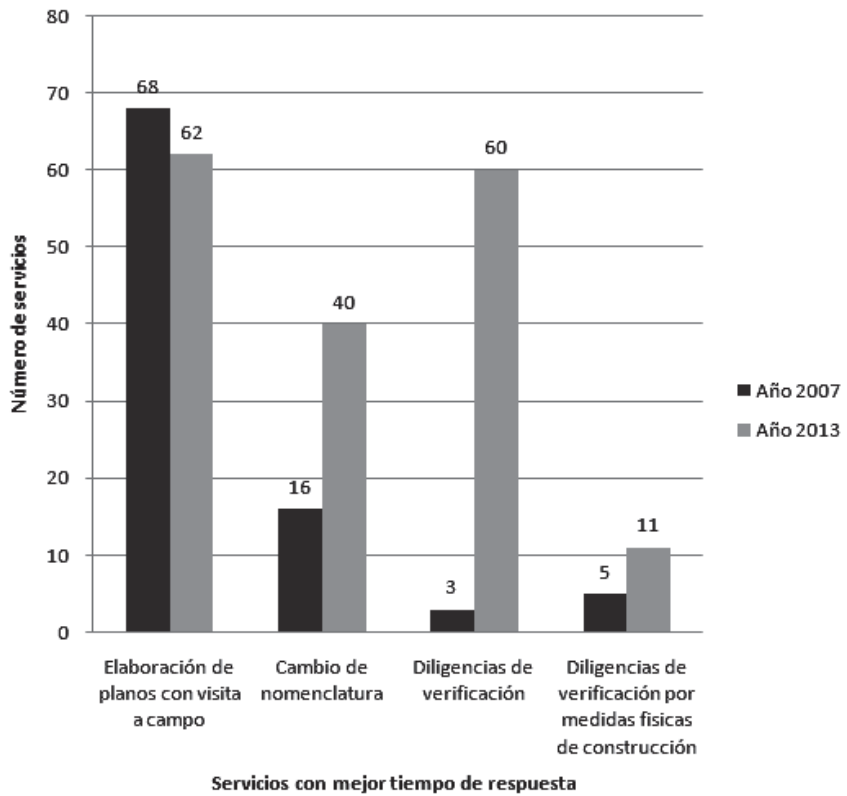

Figura 4. Comparativo de tiempo de respuesta de servicios catastrales. 


\section{Reducción en el tiempo promedio de respuesta de los trámites y servicios catastrales}

Las gráficas en la Figura 4 muestran el comparativo entre el tiempo de respuesta en los servicios en el año 2007 y el tiempo que se emplea actualmente, esta información también está compulsada con el incremento de los servicios.

Algunos servicios han tenido reducción en el tiempo de respuesta, a pesar del incremento en su número; otros, si bien han mantenido el tiempo de respuesta que establece el control de calidad del catastro, también han aumentado considerablemente el número de servicios atendidos, lo que demuestra que ha crecido la eficiencia en la atención que presta el catastro a la ciudadanía.

\section{Incremento en la recaudación fiscal por concepto del impuesto predial}

La gráfica de la Figura 5 muestra el aumento que ha tenido la recaudación del impuesto predial por la modernización en el Catastro a partir de su implementación en el año 2009, sin considerar la inflación monetaria.

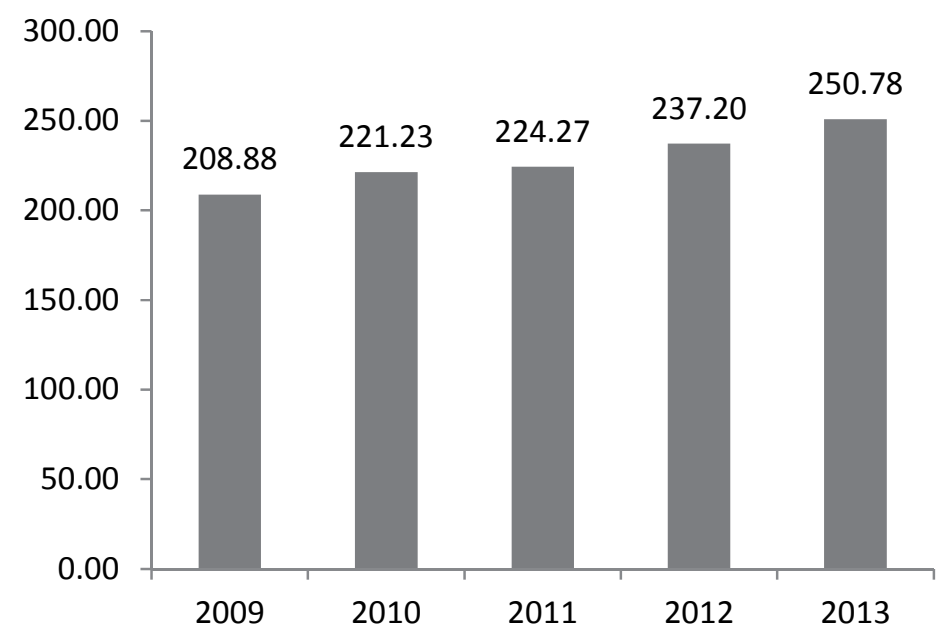

Cantidades en millones de pesos

Figura 5. Recaudación del Impuesto Predial.

Compartición, uso y aprovechamiento de la información catastral por otras áreas del municipio

Los sistemas diseñados en la Dirección de Catastro son la base para la consulta y geolocalización de la información del municipio. Por medio del folio catastral del predio que se utiliza para todo el municipio, se realizan en sistema los trámites de 
diversas dependencias, desde la consulta de un predio hasta el pago del impuesto predial e, incluso, el servicio para una factibilidad de uso de suelo.

\section{Conclusiones}

El Proyecto de Modernización Catastral del Municipio de Mérida tuvo como principal beneficio un cambio en la cultura de la institución, toda vez que pasó de ser una unidad administrativa que proporcionaba servicios de calidad a una institución que innova servicios y procedimientos; el proyecto no fue un cambio puntual, sino el principio de un cambio permanente en busca del mejoramiento continuo. Esto ha propiciado que los usuarios de servicios sean más exigentes $\mathrm{y}$, a su vez, que los colaboradores estén más dispuestos a emprender nuevos proyectos. Así se creó un círculo virtuoso de calidad creciente.

El Catastro del Municipio de Mérida aprovechó la oportunidad de demostrar que con un diagnóstico, planeación, ejecución y supervisión adecuados se pueden lograr objetivos de mejora tangibles para el ciudadano y de alta satisfacción profesional para los propios colaboradores. Sin embargo, esta misma situación obliga a ser proactivos $\mathrm{y}$, a pesar de las limitaciones presupuestales, a emprender nuevas formas de hacer mejor las cosas. Siempre se debe reconocer que existen oportunidades de mejora y saber que en un ambiente interdisciplinario e interinstitucional se pueden corregir fallas y evitar obstáculos en los objetivos trazados.

El futuro de la institución está precisamente en la implementación y mejora de servicios de calidad, en el conocimiento de cuáles son los avances en las disciplinas relacionadas con su actuar y en encontrar la manera de aprovecharlos mediante la adaptación a las necesidades propias de la institución y sus usuarios. Encontrar nuevos caminos de manera continua, ser autocríticos y objetivos para hacer mejor las cosas, ésa es la intención del personal que labora en el Catastro de Mérida.

\section{Bibliografía}

Ayuntamiento de Mérida, Yucatán, México (2008). “Diagnóstico y Plan de Acción del Catastro de Mérida, Yucatán”.

INEGI (2008). Proyecto Ejecutivo del "Programa de Modernización y Fortalecimiento Catastral".

(2010). "Norma Técnica sobre Domicilios Geográficos", publicada en el Diario Oficial de la Federación del 12 de noviembre, <http://www.snieg. $\mathrm{mx} /$ contenidos/espanol/Normatividad/Normatividad_Vigente/Archivos_NV/Nor ma_Tecnica_sobre_Domicilios_Geograficos.pdf $>$.

(2010). "Norma Técnica para el Sistema Geodésico Nacional", publicada en el Diario Oficial de la Federación del 23 de diciembre, <http://www. 
snieg.mx/contenidos/espanol/Normatividad/Normatividad_Vigente/Archivos_N V/Norma_Tecnica_para_el_Sistema_Geodesico_Nacional.pdf $>$. , (2012). "Norma Técnica para la Generación, Captación e Integración de Datos Catastrales y Registrales con Fines Estadísticos y Geográficos", publicada en el Diario Oficial de la Federación del 16 de enero, <http://www. snieg.mx/contenidos/espanol/Normatividad/Normatividad_Vigente/Archivos_N V/Norma_Tecnica_Datos_Catastrales.pdf $>$. 